Portland State University

PDXScholar

Economics Faculty Publications and

Presentations

Economics

$11-27-2015$

\title{
Environmental Sustainability in a Sraffian Framework
}

Robin Hahnel

Portland State University

Follow this and additional works at: https://pdxscholar.library.pdx.edu/econ_fac

Part of the Economics Commons

Let us know how access to this document benefits you.

Citation Details

Hahnel, Robin, "Environmental Sustainability in a Sraffian Framework" (2015). Economics Faculty

Publications and Presentations. 85.

https://pdxscholar.library.pdx.edu/econ_fac/85

This Post-Print is brought to you for free and open access. It has been accepted for inclusion in Economics Faculty Publications and Presentations by an authorized administrator of PDXScholar. Please contact us if we can make this document more accessible: pdxscholar@pdx.edu. 


\title{
ENVIRONMENTAL SUSTAINABILITY IN A SRAFFA FRAMEWORK
}

\author{
By Robin Hahnel ${ }^{1}$ for URPE at ASSAs, January 2016
}

\begin{abstract}
This article expands the Sraffa framework to address environmental sustainability by showing how to define and measure what ecological economists call "throughput" and increases in throughput efficiency. In the process it clarifies issues that are often muddled in the steady-state and de-growth literatures.
\end{abstract}

As long as leisure is more enjoyable than work on average, increases in labor productivity are socially beneficial. However, besides labor, primary inputs from "nature" are also needed to produce goods and services. And now that we no longer live in a mostly empty world, now that deterioration of the natural environment has become a prime concern, now that we can illafford further increases in what ecological economists call "throughput" in general, and now that particular components of throughput such as greenhouse gas emissions must be dramatically reduced to avoid catastrophic consequences; increases in throughput efficiency are also clearly socially desirable.

Whenever we apply labor to the economy we generate a surplus of produced goods, but, loosely speaking, we also "use up" some of nature. This problem is invisible in the simple Sraffa model where the only primary input is homogeneous labor and there are no primary inputs from nature. We could continue to sidestep the problem even while recognizing that production uses natural resources if we stipulate that whenever we apply the entire labor force to the economy we never use up more of nature than is regenerated naturally during the year. This is essentially what would be the case if the world were still "empty," in the words of ecological economist Herman Daly, and therefore nature were infinitely bounteous compared to the

\footnotetext{
${ }^{1}$ Robin Hahnel is Professor Emeritus from American University, Research Affiliate at Portland State University, Visiting Professor at Lewis and Clark College, and CoDirector of Economics for Equity and the Environment. robinhahnel@ comcast.net.
} 
magnitude of throughput generated by human economic activity. However, once the "scale" of the economy grows sufficiently and throughput grows large relative to the size, or "carrying capacity" of nature, we need to weigh how much we are depleting nature when we work compared to how large a surplus of produced goods we are getting.

The Sraffian theory of price and income distribution has proven to be well suited to accommodating multiple primary inputs from nature and rental payments to their owners. Building on the work of Schefold (1971) and von Neumann (1945), Abraham-Frois and Berrebi (1979, chapter 5) provided an early treatment that most importantly confirmed that the negative relation among distributive variables holds in a model that includes rents paid to owners of primary inputs from the natural environment. And there is now an extensive literature elaborating what we might call the "general Sraffa model" of price and income determination which accommodates not only "heterogeneous" nature, but also "heterogeneous" labor and fixed as well as circulating capital. Joint production was the key theoretical innovation that Sraffa (1960, Part II) himself, and others who followed in his tradition such as Gilbert Abraham-Frois and Edmond Berrebi (1979, chapter 3), Luigi Pasinetti (1980), Sergio Parinello (1983), Bertram Schefold (1989, Part II), and Heinz Kurz and Neri Salvadori (1995, chapters 7,8,9,10,11, and 12) discovered to be of great help in completing a "classical" theory of price and income determination. ${ }^{2}$

However, beyond taking rent into account when explaining relative price formation, few who work in the Sraffian tradition have used their framework to analyse the detrimental effects of human economic activity on the environment. Bertram Schefold (1985) acknowledges the importance of environmental constraints for rendering a "classical" theory of growth relevant to the modern age. And Gehrke and Lager (1995) use the Sraffian framework to analyse potentially perverse effects of a tax on energy on choice of technique. But nobody has attempted to formally model environmental sustainability in a Sraffian framework. For the most part multisectoral, general equilibrium work on environmental constraints on economic growth has been done by economists working in what came to be

\footnotetext{
${ }^{2}$ Because exhaustible resources raise fundamental issues about what a steady state or long period analysis means, this has proven to be one area in which Sraffians have struggled to agree on how best to incorporate insights captured by Hotelling's Rule into their analysis of price and income determination. See Ravagnani (2008) for a review of what has been at times a contentious debate.
} 
known as the "material balances approach" pioneered by Ayres and Kneese (1969), who used it to support their argument that external effects were likely to be prevalent. Rudiger Pethig, a major contributor himself, provides an excellent historical evaluation of the material balances approach in Pethig (2003). However those working in this tradition, which include Charles Perrings (1986, 1987) and Baumgärtner and Jost (2000), have been primarily concerned with technical issues such as taking the conservation of matter, increasing entropy, and cumulative uncertainty into account -- all of which are peripheral to the issues addressed in this article.

Section 1 presents the Sraffa model and some well-known results regarding price and income determination -- first when the only primary input is homogeneous labor, and then when there are multiple primary inputs, including different inputs from the natural environment. Section 2 introduces the treatment of technical change in the Sraffa framework. Section 3 explains how the overall increase in labor productivity due to a particular change in technology in a particular industry can be rigorously measured in the Sraffa model. Section 4 explains how to model what ecological economists call environmental "throughput" in the Sraffa framework, and how increases in throughput-efficiency can also be rigorously measured. Section 5 presents a first attempt to define environmental sustainability in a Sraffa framework. Section 6 highlights the importance of the relationship between the rate of growth of labor productivity and the rate of growth of throughput efficiency, and in the process helps distinguish between "sense" and "nonsense" in the steady-state and de-growth literatures. Section 7 discusses implications of the fact that nature is no more homogeneous than is labor, but is, in fact, heterogeneous in meaningful ways.

\section{Price and Income Determination in the Sraffa Framework ${ }^{3}$}

Assume the square matrix of produced input coefficients, A, is non-negative, indecomposable, and productive. Assume the row vector of direct, hourly, labor input coefficients, $\mathbf{L}$, is strictly positive. If we assume a uniform rate of profit in all industries, and assume that employers must pay only for produced inputs in advance, we can write the price and income equations for the economy as: $(1+r) \mathbf{p A}+w \mathbf{L}=\mathbf{p}$ where $r$ is the uniform rate of profit, $w$ is the hourly wage rate, and $\mathbf{p}$ is the row vector of relative prices for produced goods. It is well known that:

${ }^{3}$ For a rigorous demonstration of the results in this section see Hahnel (2016b). 
- For all permissible values of $(\mathrm{r}, \mathrm{w})$ there exists a vector of all positive relative prices for the income-price system: $(1+\mathrm{r}) \mathbf{p} \mathbf{A}+w \mathbf{L}=\mathbf{p}$.

- This vector is unique for all permissible values of $(\mathrm{r}, \mathrm{w})$, but changes, in general, when we change from one permissible combination of $(\mathrm{r}, \mathrm{w})$ to another.

- There is a negative relationship between the two distributive variables. In other words, when either $\mathrm{r}$ or $\mathrm{w}$ rises, the value of the other distributive variable must fall.

- If the column output vector for the economy, $\mathbf{x}^{*}$, is an eigenvector of A, i.e. if we produce output in proportions equal to what Sraffa called his "standard commodity," then the negative relation between the wage and profit rates is linear, and can be written as: $1=\mathrm{w}+(1 \backslash \mathrm{R}) \mathrm{r}-\mathrm{\text {-where }}$ $\mathrm{R}$ is the maximum value for $\mathrm{r}$ corresponding to a wage rate of zero, and for convenience the amount of labor applied, $\mathbf{L x}$, has been set equal to one unit, and the relative price vector has been normalized so the value of net output, $\mathbf{p}[\mathbf{I}-\mathbf{A}] \mathbf{x}$, is equal to one.

What if, in addition to homogeneous labor, a second homogeneous, "primary," non-produced input traditionally thought of as "land" is needed for production? Assume $\mathbf{T}$ is a strictly positive row vector of direct land input coefficients measured in acres and $u$ is the rent per acre. Again, if we assume that only produced inputs must be paid for in advance, i.e. that both wages and rent can be paid for out of revenues at the end of the production period, we can write the price and income equations for the economy as: $(1+\mathrm{r}) \mathbf{p} \mathbf{A}+\mathrm{w} \mathbf{L}+\mathrm{u} \mathbf{T}=\mathbf{p}$. In this case it can be shown that:

- For all permissible values of $(\mathrm{r}, \mathrm{w}, \mathrm{u})$ there exists a vector of all positive relative prices for the income-price system: $(1+r) \mathbf{p} \mathbf{A}+w \mathbf{L}+u \mathbf{T}=\mathbf{p}$.

- This vector is unique for all permissible values of $(\mathrm{r}, \mathrm{w}, \mathrm{u})$, but changes, in general, when we change from one permissible combination of $(r, w, u)$ to another. 
- There is a negative relationship between all three distributive variables. In other words, when the value of any distributive variable rises, the value of one or both of the other distributive variables must fall.

- If the column output vector for the economy, $\mathbf{x}^{*}$, is an eigenvector of A, i.e. if we produce output in proportions equal to Sraffa's "standard commodity," then the negative relation between $\mathrm{r}$, w, and $\mathrm{u}$ is linear and can be written as: $1=w \mathbf{L} \mathbf{x}^{*}+\mathbf{u} \mathbf{T} \mathbf{x}^{*}+(1 \backslash \mathrm{R}) \mathrm{r}$ where again for convenience $\mathbf{L x}$ and $\mathbf{p}[\mathbf{I}-\mathbf{A}] \mathbf{x}$ have each been set equal to one.

Moreover, this price-income system can easily be generalized to account for both heterogeneous labor and heterogeneous non-labor primary inputs from "nature." This is important because sometimes carpentry labor is needed to produce things, while other times welding labor is needed. In which case an hour of one is not equivalent to an hour of the other, and they are not generally paid the same wage rate. Similarly, when producing food, an acre of fertile river-bottom land is not the same as an acre of rocky land on a steep slope, and they do not command the same rent. More importantly, besides the fact that land itself is heterogeneous there are many other non-labor primary inputs such as iron ore, oil, and timber needed in production, which command rental payments as well. In the Sraffa framework to account for heterogeneous labor we simply make our row vector of labor input coefficients, $\mathbf{L}$, into a matrix with as many rows as we have different kinds of labor, and we make our hourly wage rate, $w$, into a row vector, w, of hourly wage rates for each category of labor. To account for all of the heterogeneous, primary inputs from nature needed for production we simply make our row vector of "nature" input coefficients, $\mathbf{T}$, into a matrix with as many different rows as we have different kinds of primary inputs from nature that are needed for production, and we make our rent per acre, $u$, into a row vector, $\mathbf{u}$, of rental rates per unit of each category of nature used in production. In which case:

- The negative linear relations among all of the distributive variables becomes: $1=\mathbf{w} \mathbf{L} \mathbf{x}^{*}+\mathbf{u} \mathbf{T} \mathbf{x}^{*}+(1 \backslash \mathrm{R}) \mathbf{r}$ where again for convenience $\mathbf{L x}$ and $\mathbf{p}[\mathbf{I}-\mathbf{A}] \mathbf{x}$ have each been set equal to one.

In sum, this is how the Sraffa model explains the relations among distributive variables in capitalist economies, and how it explains relative price determination for any permissible values for the distributive variables, (w, $\mathbf{u}$, r) and any given technologies, $\{\mathbf{A}, \mathbf{L}, \mathbf{T}\}$. But what happens when capitalists discover new ways to produce things? For example, what happens when 
capitalists in industry $\mathrm{j}$ can choose between continuing to use $[\mathbf{a}(\mathrm{j}), \mathbf{L}(\mathrm{j}), \mathbf{T}(\mathrm{j})]$, or use $\left[\mathbf{a}(\mathrm{j})^{\prime}, \mathbf{L}(\mathrm{j}){ }^{\prime}, \mathbf{T}(\mathrm{j})^{\prime}\right]$ instead?

\section{Technical Change in the Sraffa Framework}

While the Sraffa model does not claim to shed light on what enhances or retards the discovery of new technologies, it is well-suited to analysing how any new discoveries will be treated and their affects.

Choice of Technique: To know whether capitalists will replace an old technique with a new one we simply compare the cost of producing a unit of output using the old and new technologies at current prices, wages, and rents: If $\mathbf{p a}(\mathrm{j})^{\prime}+\mathbf{w L}(\mathrm{j})^{\prime}+\mathbf{u T}(\mathrm{j})^{\prime}<\mathbf{p a}(\mathrm{j})+\mathbf{w L}(\mathrm{j})+\mathbf{u T}(\mathrm{j})$ profit maximizing capitalists in industry $\mathrm{j}$ will adopt the new technology, and otherwise they will not. Technological changes which lower production costs at current prices and values for distributive variables are often called viable.

Technical change and prices: Sraffa (1960) clarified how new technologies affect relative prices by distinguishing between basic goods which either directly or indirectly enter into the production of all goods, and non-basic goods which do not: Sraffa demonstrated that technical changes in a basic industry will necessarily affect the entire relative price system. While technical changes in a non-basic industry will simply lower its own relative price, and the prices of any other non-basics if it should happen to enter into their production.

Technical change and income distribution: How the introduction of viable technical changes might affect the rate of profit in the economy puzzled political economists for over a hundred years. It long appeared that the answer to this question even in a simple framework where homogeneous labor is the only primary input was very complicated, and quite possibly not definitive. A capitalist in industry $\mathrm{j}$ would not implement a new technology unless it was less costly and therefore more profitable than the existing technology in the short-run, i.e. unless it was cost reducing a current prices, wages, and rents, or "viable." However, once all capitalists in industry $\mathrm{j}$ adopted the new, lower-cost technology, absent barriers to entry and exit the entire price system would presumably adjust to eliminate "super profits" in industry j. In which case who could say whether at these new prices, p', the new uniform rate of profit in the economy would turn out to be higher or lower than the old uniform rate of profit. 
Marx, of course, famously argued that after prices adjusted to eliminate super profits, viable, capital-using, labor-saving technical change would ultimately put downward pressure on the rate of profit. However, Okishio (1961) proved that the effect on the rate of profit is exactly the opposite: For A non-negative, indecomposable, and productive, as long as the real wage remains constant, introduction of any viable technical change -- including any viable, capital-using, labor-saving changes -- must raise the uniform rate of profit in the economy. And even if the economy is decomposable, and the viable change occurs in a non-basic industry, Okishio proved that the rate of profit in the economy would remain the same. So as far as income distribution is concerned, Okishio proved that the only technical changes that a profit maximizing capitalist would ever implement cannot lower the rate of profit in the economy, and must increase the rate of profit if the change takes place in a basic industry -- provided we hold the only other distributive variable, the real wage, constant.

Technical change and labor productivity: As explained in the next section, it is well known that if we only wish to know if a viable technical change will raise or lower labor productivity, i.e. how a viable change will affect labor productivity qualitatively, all we need to do is compare labor values in the economy before and after a technical change is introduced. However, in section 3 we explain how a new theorem provides a way to calculate quantitatively how much any technical change in any industry will increase or decrease overall labor productivity.

Technical change and throughput efficiency: Since environmental deterioration is largely a consequence of increases in throughput, being able to track throughput, and analyse the effects of technical change on throughput efficiency is of paramount importance. Section 4 deploys the same method used in section 3 for measuring the size of any changes in labor productivity to measure how much any technical change in any industry increases or decreases overall throughput efficiency.

\section{Technical Change and Labor Productivity}

The vector of labor values, $\mathbf{V}=\mathbf{L}[\mathbf{I}-\mathbf{A}]^{-1}$, tells us how many hours of labor it takes, both directly and indirectly, to produce each good in the economy. By comparing $\mathbf{V}=\mathbf{L}[\mathbf{I}-\mathbf{A}]^{-1}$ to $\mathbf{V}^{\prime}=\mathbf{L}^{\prime}\left[\mathbf{I}-\mathbf{A}^{\prime}\right]^{-1}$ we can immediately tell if a technical change has increased or decreased labor productivity. If $\mathbf{V}^{\prime} \leq \mathbf{V}$ it 
now takes less labor to produce at least one good and no more labor to produce any good than it used to, so labor productivity has definitively increased. Conversely, if $\mathbf{V} \leq \mathbf{V}$ ' labor productivity has decreased. John Roemer (1981) called technological changes where $\mathbf{V}^{\prime} \leq \mathbf{V}$ progressive, and changes where $\mathbf{V} \leq \mathbf{V}$ ' retrogressive. ${ }^{4}$

However, comparing labor values before and after any technical change only tells us if labor productivity has increased or decreased. It does not tell us quantitatively how much productivity has changed. Part iii of the theorem below, proved in Hahnel (2016a), explains how to calculate the size of changes in labor productivity in the economy as a whole stemming from any technological change in a particular industry by comparing the dominant eigenvalues of a particular socio-technology matrix for the economy as a whole before and after the change.

Dominant eigenvalues, profitability, and productivity: For any given $\mathbf{A}$ and $\mathbf{L}$ there are many $\mathbf{A}^{*}=[\mathbf{A}+\mathbf{b} \mathbf{L}]$ corresponding to different real wage vectors, $\mathbf{b}$. For any such $\mathbf{A}^{*}$ non-negative, indecomposable, and productive:

(i) If a technical change reduces $\operatorname{dom}\left(\mathbf{A}^{*}\right)=\beta$, for any $\mathbf{A}^{*}$ corresponding to any $\mathbf{b}$, then provided the real wage, $\mathbf{b}$, remains unchanged the uniform rate of profit in the economy, $r$, must rise. (This part simply reiterates the Okishio theorem.)

(ii) For any $\tilde{\mathbf{b}}$ sufficiently high to reduce the initial rate of profit in the economy to zero so that $\operatorname{dom}\left(\mathbf{A}^{*}\right)=\beta=1$, if a technical change reduces the economy's dominant eigenvalue, i.e. if $\operatorname{dom}\left(\mathbf{A}^{*}\right)=\operatorname{dom}\left(\mathbf{A}^{\prime}+\tilde{\mathbf{b}} \mathbf{L}^{\prime}\right)=\beta^{\prime}<1$, it increases overall labor productivity and is therefore progressive. ${ }^{5}$

\footnotetext{
${ }^{4}$ For a single technical change either (i) $\mathbf{V}^{\prime} \leq \mathbf{V}$, (ii) $\mathbf{V} \leq \mathbf{V}^{\prime}$, or (iii) $\mathbf{V}=\mathbf{V}^{\prime}$. This is because in the industry where the change took place either $v(j)$ fell, rose, or remained the same. If it fell and it enters into the production of another good, either directly or indirectly, the value of that good must also fall since there was no change in its input coefficients. If it does not enter into the production of another good, either directly or indirectly, the value of that good will stay the same. Similarly, if $v(j)$ increases, the value of other goods must either increase or remain the same. Finally, if $v(j)$ itself does not change, then no values will change.

${ }^{5}$ If $\beta^{\prime}>1$ the technical change is retrogressive, and if $\beta^{\prime}=1$ the technical change is neutral.
} 
(iii) The size of the increase in overall labor productivity is $\rho=\left(1-\beta^{\prime}\right)$, where $\beta^{\prime}=\operatorname{dom}\left(\mathbf{A}^{* \prime}\right)=\operatorname{dom}\left(\mathbf{A}^{\prime}+\tilde{\mathbf{b}} \mathbf{L}^{\prime}\right)$.

Suppose, for example, we find that $\beta^{\prime}$, the dominant eigenvalue for the new socio-technology matrix [A'+ $\tilde{\mathbf{b}}_{\mathbf{L}}{ }^{\prime}$ ] equals 0.97 , whereas $B$, the dominant eigenvalue for the original socio-technology matrix $[\mathbf{A}+\tilde{\mathbf{b}} \mathbf{L}]$, was equal to 1.00. In this case labor productivity has increased by $\rho=\left(\beta-\beta^{\prime}\right) / \beta=(1.00$ $0.97) / 1.00=.03$, or $3 \%$. If people next year work the same number of hours as they did this year they will produce $3 \%$ more goods. Or, if people next year consume exactly what they consumed this year they could work $3 \%$ fewer hours than last year. On the other hand, suppose we find that the dominant eigenvalue for the new socio-technology matrix [ $\left.\mathbf{A}^{\prime}+\tilde{\mathbf{b}} \mathbf{L}^{\prime}\right], \beta^{\prime}$, equals 1.05 . In this case labor productivity has decreased by $\rho=\left(\beta-\beta^{\prime}\right) / \beta=$ $(1.0-1.05) / 1.00=-.05$, or $5 \%$, and people will either produce $5 \%$ less goods, or have to work $5 \%$ more hours. In sum, by comparing the dominant eigenvalues of the new and old socio-technology matrices for the economy, using a real wage vector $\tilde{\mathbf{b}}$ high enough to reduce the rate of profit in the original economy to zero, we can calculate precisely how much labor productivity in the economy as a whole is increased or decreased due to any particular technological change in any particular industry.

\section{Technical Change and Throughput Efficiency}

Ecological economists define throughput as physical inputs from the natural environment used as inputs in production processes such as iron ore and top soil, as well as physical outputs of production (usually thought of as waste or pollution) such as airborne particulate matter and greenhouse gases released back into the natural environment.

It is important to recognize a difference between how inputs from nature can be treated for purposes of explaining prices and income distribution from how they must be treated for purposes of analysing how production causes nature to deteriorate. In the first case all we need to know, for example, is how many acres of land must be available for production to take place since the objective is simply to account for the rental payment its owner will receive per acre. From that perspective it makes no difference what happens to the acre of land. It makes no difference if its use in production causes it to deteriorate in some way or not. But throughput is precisely about deterioration, most often conceived as deletion of a scarce natural resource 
or as reduction in the storage capacity of a natural sink. If land used in production does not deteriorate, throughput is zero even though rent per acre is positive. And if land does deteriorate, for example because top soil is washed away, then the throughput is the lost top soil which we can measure in cubic feet, not the number of acres of land which obviously does not change.

To emphasize that the amount of any natural resource or sink service that must be present for production to take place is not necessarily the same as the amount of the natural resource or sink service that is "used up," "deleted from nature," or more generally, deteriorates in a quantifiable way, we use different letters to represent these inputs. Whereas $t(\mathrm{ij})$ was the number of units of a non-produced natural resource or sink service $\mathrm{i}$ that must be present to produce a unit of good $\mathrm{j}$, without regard to what happens to $\mathrm{i}$; we define $\mathrm{h}(\mathrm{ij})$ as the number of units of the non-produced natural resource or sink service $\mathrm{i}$ that production of a unit of $\mathrm{j}$ uses up, deletes, or otherwise causes to deteriorate. Whereas $\mathbf{T}$ was the vector of appropriate coefficients for price and income determination, $\mathbf{H}$ is the appropriate vector of coefficients for tracking the detrimental effects of production activity on the natural environment.

Throughput must be measured in some appropriate physical units such as tons of iron ore, cubic meters of top soil, pounds of particulate matter, and cubic tons of carbon dioxide -- which means there is no such thing as "throughput from nature in general" that can be meaningfully measured. Instead there is iron ore, top soil, particulate matter, and carbon throughput, etc. - each of which can be measured in appropriate, but different physical units. In other words, just as "labor" is not actually homogeneous, "nature" is not homogeneous, but instead heterogeneous in meaningful ways. However, just as the Sraffian analysis began by treating labor as if it were homogeneous in order to be able to talk about labor productivity in general, we will again begin by treating nature as if it were homogeneous in order to be able to talk about throughput and throughput efficiency in general -postponing discussion of nature's heterogeneity to section 7 .

Just as it does not matter what unit we use to measure inputs of homogeneous labor - we have used hours, but could just as well have used days, or years -- it does not matter what unit we use to measure inputs from homogeneous nature used up in production. The problem is that while appropriate units come to mind whenever we talk about some particular part 
of nature such as oil, soil, old growth timber, airborne particulate matter, greenhouse gases, etc., there is no conventional unit of measurement that comes to mind when we think about nature as a homogeneous input in human production processes. When faced with a similar dilemma others writing about "ecological footprints" use an "acre" as their unit of measurement. But since this can lead to confusion we use a "green" instead as our name for a unit of homogeneous nature.

At this point we need to distinguish between technical change that reduces the amount of labor "used up" to make goods and services, i.e. that increases labor productivity, and technical change that reduces the amount of nature "used up" making goods and services, i.e. that increases throughput efficiency. Fortunately, the Sraffa framework is well-suited to helping us measure the effects of the second kind of socially beneficial technical change very much as we measure the first.

Assume there is only one primary input from nature used up in production. Define $h(j)$ as the direct "nature" input coefficient - the number "greens" used up directly in production of a unit of $\mathrm{j}$-- analogous to $1(\mathrm{j})$ the direct (homogeneous) labor input coefficient - the number of hours of labor "used up" directly in production of a unit of $\mathbf{j}$-- with $\mathbf{H}$ the row vector of direct nature input coefficients, analogous to $\mathbf{L}$ the row vector of direct labor input coefficients. Just as the number of hours of labor used up both directly and indirectly to make every good is given by $\mathbf{V}=\mathbf{L}[\mathbf{I}-\mathbf{A}]^{-1}$, the number of greens used up both directly and indirectly to make every good is given by $\mathbf{N}$ $=\mathbf{H}[\mathbf{I}-\mathbf{A}]^{-1}$ And just as the first kind of technical improvements are changes in the a(ij)'s and/or 1(j)'s that reduce the v(j)'s, and thereby increase the productivity of labor; the second kind of technical improvements are changes in the a(ij)'s and/or $h(j)$ 's that reduce the $n(j)$ 's, and thereby increase nature throughput efficiency. But if there is a single number, $\rho$, which represents how much labor productivity has changed from one year to the next due to some particular technical change in some particular industry, shouldn't there also be a single number that represents how much throughput efficiency has changed due to some particular technical change in some industry from one year to the next?

Ignore for the moment that we need to apply labor to produce goods and services, just as we previously ignored that we need inputs from nature to produce goods and services in the simple Sraffa model. So instead of 1(j)'s 
and the row vector $\mathbf{L}$ we now have only $h(j)$ 's and the row vector $\mathbf{H}$, and we can write the Sraffa price equations as:

$(1+r)[\mathbf{p A}+\mathbf{m} \mathbf{H}]=\mathbf{p}$ where $\mathrm{m}$ is the "rent" per green of throughput used up which capitalists must pay to owners of nature. ${ }^{6}$ With $\mathrm{m}=\mathbf{p d}$, where $\mathbf{d}$ is a vector of consumption goods owners of nature can purchase with their rental payment per green used up, this becomes:

$$
(1+\mathrm{r})[\mathbf{p} \mathbf{A}+\mathbf{p d H}]=(1+\mathrm{r}) \mathbf{p}[\mathbf{A}+\mathbf{d} \mathbf{H}]=(1+\mathrm{r}) \mathbf{p} \mathbf{A}^{+}=\mathbf{p}, \text { where }[\mathbf{A}+\mathbf{d} \mathbf{H}]=\mathbf{A}^{+}
$$

Just as before, we must choose the vector $\tilde{\mathbf{d}}$ carefully so that $\mathrm{r}=0$. Let the vector $\tilde{\mathbf{d}}$ be such that $\operatorname{dom}[\mathbf{A}+\tilde{\mathbf{d}} \mathbf{H}]=\alpha=1$. Calculate $\operatorname{dom}\left[\mathbf{A}^{\prime}+\tilde{\mathbf{d}} \mathbf{H}^{\prime}\right]=\alpha$ ' and define $\rho=\left(1-\alpha^{\prime}\right)$ as before.

This time $\rho$ represents how much nature throughput efficiency has increased. To distinguish between the two different kinds of technological progress, from now on we will call increases in labor productivity $\rho(1)$, and increases in nature throughput efficiency $\rho(\mathrm{n})$. We formulate this important result as a theorem:

Dominant Eigenvalues and Throughput Efficiency: $\rho(n)=\left(1-\alpha^{\prime}\right)$ is the change in throughput efficiency in the economy where $\alpha^{\prime}=\operatorname{dom}\left[\mathbf{A}^{\prime}+\tilde{\mathbf{d}} \mathbf{H}^{\prime}\right]$, and $\tilde{\mathbf{d}}$ is chosen such that $\operatorname{dom}[\mathbf{A}+\tilde{\mathbf{d}} \mathbf{H}]=\alpha=1$.

It is also helpful to distinguish between (1) capital-using, labor-saving (CULS) technical changes: $\mathbf{A} \leq \mathbf{A}^{\prime}$ and $\mathbf{L}^{\prime} \leq \mathbf{L}$, (2) capital-saving, labor-using (CS-LU) technical changes: $\mathbf{A}^{\prime} \leq \mathbf{A}$ and $\mathbf{L} \leq \mathbf{L}^{\prime}$, (3) capital-using, naturesaving (CU-NS) technical changes: $\mathbf{A} \leq \mathbf{A}^{\prime}$ and $\mathbf{T}^{\prime} \leq \mathbf{T}$, and (4) capitalsaving, nature-using (CS-LU) technical changes: $\mathbf{A}^{\prime} \leq \mathbf{A}$ and $\mathbf{T} \leq \mathbf{T}^{\prime}$. Let us pause and review where we are.

1. We can only calculate a single measure of throughput efficiency, $\rho(n)$, when we have a single primary input from "nature." While unfortunate, this is hardly surprising because we can only calculate a single measure of increases in labor productivity, $\rho(1)$, when labor is presumed to be homogeneous. Multiple primary inputs from nature render it impossible to

${ }^{6}$ This is the rent owners of nature would presumably receive per unit used up if production were possible without any labor, or if the wage rate were equal to zero. 
calculate a single measure of increases in throughput efficiency -- just as heterogeneous labor renders it impossible to calculate a single measure of increases in labor productivity. ${ }^{7}$

2. Just as we have to be careful not to confuse a reduction in a direct labor input coefficient, $1(\mathrm{j})$, with a reduction in the total amount of labor used up both directly and indirectly to make a unit of $\mathrm{j}, \mathrm{v}(\mathrm{j})$; we must not confuse a reduction in a direct nature input coefficient, $h(j)$, with a reduction in the total amount of nature used up both directly and indirectly to make a unit of $\mathrm{j}, \mathrm{n}(\mathrm{j})$. It is possible that a capital-saving, nature-using (CS-NU) technical change might lower the total amount of nature needed to make commodities even though it increases the amount of direct nature needed. In other words, it is $\mathbf{N}$, not $\mathbf{H}$ that we should care about, just as it is $\mathbf{V}$, not $\mathbf{L}$ that matters.

3. Reductions in 1(j)'s improve only labor productivity without affecting throughput efficiency, and reductions in $\mathrm{h}(\mathrm{j})$ 's improve only throughput efficiency without affecting labor productivity. On the other hand, any reduction in an a(ij) will improve both labor productivity and throughput efficiency. However, any capital using, labor saving (CU-LS) technical change will necessarily reduce throughput efficiency, and any capital using, nature saving (CU-NS) change will necessarily reduce labor productivity.

4. Finally, it is worth considering what happens when capitalists choose technologies in a context where throughput from nature is under-priced. Assume in the extreme that the price of using nature is zero. In this case there is no incentive for capitalists to choose pure nature-saving technologies (NS), much less capital-using, nature-saving technologies, NS-CU. Worse still, when capitalists discover viable CU-LS technologies they will adopt them without fail. But since they are CU, i.e. they use more of some a(ij)'s, they necessarily use more nature indirectly as well: Viable CU-LS changes will make $\mathbf{N}^{\prime}>\mathbf{N}$ and $\rho\left(\right.$ n) negative. ${ }^{8}$ There is every reason to believe that a great deal of technical change during the past few hundred years implemented by profit maximizing capitalists did just this. Certainly in the

\footnotetext{
7 Although we can calculate how much throughput efficiency increases for each component of heterogeneous nature individually, as discussed in section 7 .

${ }^{8}$ The only circumstance under which a CU-LS technical change might not increase $\mathbf{N}$ and therefore make $\rho(n)$ negative is if it also just happened to be NS as well, i.e. if it was in fact a CU-LS-NS change.
} 
case of carbon emissions where the price charged for carbon "throughput" has long been zero, there was no incentive to economize on carbon throughput, and whenever capitalists discovered and implemented viable CU-LS changes they necessarily increased carbon emissions indirectly and thereby decreased carbon throughput efficiency. This phenomenon may help explain why we are now facing the possibility of cataclysmic climate change because we have overstocked the upper atmosphere with $\mathrm{CO}_{2}$.

\section{Environmental Sustainability when Nature is Homogeneous}

Assume there are only two primary inputs, homogenous labor, measured in hours, and homogeneous nature measured in greens. For convenience also assume that the size of the labor force and number of hours worked remains the same year after year. We assume that nature consists of a certain number of greens, $\underline{\text { GR}}$, which is initially just sufficient to permit full employment of the labor force. In which case, if production uses up any greens at all it is impossible to define an environmentally sustainable steady state unless nature also regenerates. So we assume that nature regenerates a certain number of greens per year, REG. ${ }^{9}$

The first condition for sustainability is that the number of greens used up as inputs in production during a year, i.e. "nature throughput," cannot exceed the number of greens regenerated during a year. Otherwise there will not be enough greens of nature to allow for production to continue at the same level as the previous year. $\mathbf{N}$ is our row vector representing the number of greens of nature needed directly and indirectly to make a unit of each produced good in the economy. So if $\mathbf{x}$ is the vector of produced outputs, $\mathbf{N x}$ represents throughput, the number of greens subtracted from GR because we produced $\mathbf{x}$ this year. To prevent GR from shrinking, we need $\overline{\mathbf{N x}} \leq$ REG. $^{10}$

\footnotetext{
${ }^{9}$ Under the assumption of a single homogeneous input from nature it is impossible for the economy to be environmentally sustainable unless nature is assumed to be renewable. Which means that discussion of sustainability when some natural resources are nonrenewable must be deferred until we consider a framework which treats nature as heterogeneous in section 7 .

${ }^{10}$ Environmental sustainability is only of concern when nature is no longer infinite in size compared to the throughput a fully employed labor force would produce. We are assuming we have left the "empty" world where $\mathbf{N x} \ll<\underline{\text { GR }}$ where it would be of no concern if $\mathbf{N x}$ exceeds GR.
} 
But even if the labor force is not growing what if labor productivity is growing? If labor productivity increases the same number of hours worked next year will produce a larger $\mathbf{x}$ than this year. In order to prevent throughput from exceeding regeneration and rendering the economy environmentally unsustainable $\mathbf{N}$ must decrease. As we have seen, the Sraffa model allows us to represent how much $\mathbf{x}$ rises due to technical changes that increase labor productivity by a single number, $\rho(1)$, and also allows us to represent how much $\mathbf{N}$ shrinks due to technical changes that increase throughput efficiency by a single number, $\rho(n)$. Provided the number of hours worked does not change, as long as $\rho(n)=\rho(1)$ throughput will not rise, but remain constant. In sum:

- The first condition for environmental sustainability is $\mathbf{N x} \leq$ REG. This establishes the level of throughput we must not surpass to maintain environmental sustainability.

- The second condition for sustainability is $\rho(n)=\rho(1)$. This keeps throughput from rising above REG even as labor productivity grows.

If either condition is violated the economy will become environmentally unsustainable.

\section{Implications for Steady-State and De-Growth Economics}

What are we to make of statements like: "Infinite economic growth on a finite planet is impossible. Only a madman or an economist would think otherwise." What are we to make of pleas to substitute the goal of a "steady state economy" for the traditional goal of increasing economic growth? What are we to make of the de-growth movement which argues that we must actually reduce output to make our economies environmentally sustainable?

The key to clear thinking on these subjects is understanding the difference between throughput and economic wellbeing. ${ }^{11}$ Our ability to rigorously model increases in labor productivity and throughput efficiency in the Sraffa

\footnotetext{
${ }^{11}$ In the real world measuring changes in economic wellbeing is very difficult, and certainly more complicated than simply looking at changes in GDP per capita. (See Hahnel 2013) However, in the Sraffa framework wellbeing is reduced simply to working less to get the same output, which we can measure quantitatively by $\rho(1)$.
} 
framework, and establish necessary and sufficient conditions for environmental sustainability, can be extremely helpful in this regard.

If we are careful to interpret the above warnings to be referring to throughput they can be very insightful. On a planet where the quantity of nature available for throughput is finite, infinite growth of throughput is, indeed, impossible -- if that is what Kenneth Boulding meant to say. Since it is increasingly apparent that many kinds of throughput have become so large that their continued growth is environmentally unstable, Herman Daly's call to strive to maintain throughput at a steady state, rather than seek to increase throughput, is sage advice - if that is what Daly meant to say. And since we know that for some parts of heterogeneous nature, such as the storage capacity for greenhouse gases in the atmosphere, maintaining throughput at present levels will prove disastrous, calling for de-growth for some kinds of throughput like carbon emissions is nothing more than simple sanity assuming that is what those in the de-growth movement are calling for.

On the other hand, if anyone claims that economic wellbeing per capita cannot continue to grow indefinitely, or that achieving environmental sustainability means that wellbeing per capita cannot grow, or must decrease, our model demonstrates quite clearly that none of these conclusions are warranted. If we keep discovering new technologies that increase labor productivity then wellbeing per capita can continue to expand. That's what $\rho(1)>0$ means. For hundreds of years we have proven capable of finding new technologies that improve our ability to produce more goods and services per hour, or what is the same thing, produce the same amount of goods and services as before in less than an hour. The pace of technological change that increases labor productivity may slacken or increase from time to time in the future, as it has in the past, but there is no reason to believe it cannot continue to increase indefinitely.

But will increases in labor productivity prove to be environmentally unstable? Clearly not if we choose to take all increases in productivity in the form of more leisure. If we continue to produce the same vector of outputs, $\mathbf{x}$, and simply do so working fewer hours, we do not increase strain on the environment. But what if we continue to work the same number of hours as labor productivity grows, and we therefore produce more goods and services than before? Doesn't this necessarily imply that throughput will be greater, and therefore that at some point further increases in labor productivity must cease if we are to avoid environmental disaster? 
Consider a worst case scenario: Assume that we take none of our increased productivity in the form of leisure, and we increase every component of $\mathbf{x}$ in the same proportion. So $[1+\rho(1)] \mathbf{x}=\mathbf{x},>\mathbf{x}$, and therefore there is no possibility of substituting less throughput intensive goods for more throughput intensive goods in consumption. Even so, as long as $\rho(n)=\rho(1)$, N'x' will be equal to $\mathbf{N x}$, and therefore $\mathbf{x}$ ' will tread no more heavily on the environment than $\mathbf{x}$ did. So, at least in theory, it is possible for hours worked to remain constant, labor productivity to rise, and throughput to remain constant provided throughput efficiency rises as fast as labor productivity. As should now be clear, it all boils down to the relationship between $\rho(n)$ and $\rho(1)$. Assuming no change in hours worked or the composition of output:

- As long as $\mathbf{N x}<$ REG, $\rho(1)$ can exceed $\rho(n)$ until throughput, $\mathbf{N x}$, reaches REG.

- Once $\mathbf{N x}=$ REG, $\rho(n)=\rho(1)$ is necessary and sufficient to maintain environmental sustainability.

- If $\mathbf{N x}>$ REG, $\rho(n)>\rho(1)$ is required to re-achieve environmental sustainability.

Nothing said here should be interpreted to deny that taking more of our productivity increases in the form of leisure rather than additional consumption will be an important part of achieving environmental sustainability in practice. Juliet Schor (1993 and 1999) has done a great deal to draw attention to the astounding fact that on average Americans work more hours today than we did forty years ago, even though we are almost twice as productive. Moreover, there is now a great deal of empirical research suggesting that further increases in average consumption in the advanced economies is no longer yielding increases in happiness or wellbeing. In which case social policy should be concentrating on shifting material consumption from those at the top to those at the bottom of the income distribution rather than increasing average consumption. Nor should anything said here be construed to imply that substituting less throughput intensive components for more throughput intensive components in our output vector, $\mathbf{x}$, will not be a crucial part of achieving environmental sustainability. And finally, nothing said here should detract attention from the fact that it is the throughput generated by the consumption of the very wealthy that is the greatest threat to the environment, and therefore 
redistribution of income and wealth is important for environmental protection as well as economic justice. In short, nothing in the abstract treatment here need detract from any of these important priorities.

However, if the modelling of environmental sustainability which the Sraffa framework facilitates can help clarify issues, eliminate misperceptions, and reduce miscommunications that have plagued attempts to grapple with one of humanity's most pressing problems it can be useful. Moreover, there are clear strategic and political implications: If lower middle class workers in the advanced economies come to think environmentalists are telling them that they must abandon hopes for a higher standard of living for their children in order to save the environment, they may be reluctant to become supporters. And if billions living in less developed economies who have yet to enjoy the benefits of economic development come to think environmentalists are telling them that they need to give up all hope of achieving economic development if the environment is to be saved, they may be reluctant to become supporters as well. What the above analysis demonstrates clearly is that environmental sustainability need not be incompatible with increases in economic wellbeing. In which case, calls for an end to growth, or de-growth to save the environment which give that impression are not only politically self-defeating, but misleading and unnecessary.

\section{Heterogeneous Nature}

No doubt many readers have engaged in the exercise which translates one's consumption behaviour into an ecological "footprint" represented as a number of "acres," and then informs you how many planet "earths" would be needed if everyone else tread on "mother nature" as heavily as you do. This may well be a useful tool for raising consciousness. However, precisely because nature is heterogeneous in meaningful ways, the ecological footprint exercise can be grossly misleading if interpreted as a useful guide to policy. Consider three components of mother nature: she provides sink services for storing greenhouse gases in the upper atmosphere, fresh water, and sand. Just as I have a "carbon footprint" we can measure in cubic meters of carbon dioxide equivalents, I also have a "fresh water footprint" we can measure in gallons, and a "sand footprint" we can measure in tons. However, unless we know whether nature, and therefore humanity, is going to run out of greenhouse gas storage capacity, fresh water, or sand first, we don't know which of my footprints is causing more environmental damage, and 
therefore treading more heavily on the environment. The answer depends on which part of heterogeneous nature is being exhausted more rapidly - the upper atmosphere, water, or sand - as well as on which part of nature we are more likely to find substitutes for. Moreover, failure to model nature as heterogeneous prevents us from exploring the beneficial effects of substituting one part of nature that is less scarce for another part that is more scarce.

Fortunately the Sraffa framework can still be helpful in the case of heterogeneous nature, whether it be different "natural resources" or different "sink services" that nature provides. It now appears that we may be exhausting nature's ability to store particular material "outputs" of production processes faster than we are using up particular raw material "inputs" from nature. However, there is no reason we cannot include multiple additions to the environment (different emissions or pollutants) along with multiple deletions from the environment (different raw materials) associated with production processes in our linear production technologies. The easiest way to do this without need to resort to the complication of joint products is to treat the output of $\mathrm{z}$ units of a pollutant as an input from a sink service which reduces the storage capacity of the sink by $\mathrm{z}$ units. ${ }^{12}$

While the Sraffa framework cannot tell us which parts of nature's many services are at greater risk, and therefore what our policy priorities should be, at least in theory it provides a way to rigorously measure throughput and increases in throughput efficiency for individual services. Simply by turning $\mathbf{H}$, our vector of direct throughput input coefficients when we assumed nature to be homogeneous, into a matrix with as many different rows as there are different kinds of services from nature we "use up" in production, in theory

12 Traditionally economists thought of a "service" from nature as a natural resource "input" like iron ore, but there is no reason the service cannot be storage of an emission like $\mathrm{CO}_{2}$. As long as iron ore used up (tons deleted from scarce reserves) and $\mathrm{CO}_{2}$ emissions (metric tons subtracted from scarce storage capacity in the upper atmosphere) are both listed as inputs in our "recipes" for producing different goods and services we can calculate throughput and changes in throughput efficiency for both iron ore and $\mathrm{CO}_{2}$ individually without resort to treating pollutants as joint products. The Sraffa framework is admirably suited to handling joint products which is required for treating fixed capital - produced inputs like machines which last for many years. But a joint product version of the Sraffa framework is more complicated and is not needed for purposes of measuring throughput, even when throughput takes the form of output "wastes" released into natural sinks. 
we can measure throughput for individual components of heterogeneous nature and calculate changes in throughput efficiency for each individually. ${ }^{13}$ In other words, in the Sraffa framework we can define and rigorously calculate carbon throughput and increases in carbon throughput efficiency, water throughput and increases in water throughput efficiency, and sand throughput and increases in sand throughput efficiency.

Since it is clear that human economic activity is exhausting some parts of nature much faster than others, this is of great practical importance. For example, scientists who have expertise in such matters tell us we need to reduce carbon throughput by more than $90 \%$ by 2050 to avoid an unacceptable risk of triggering cataclysmic climate change. While there is good reason to worry about fresh water supplies, most estimate that this problem is not reaching crisis proportions as quickly. In contrast, we can probably increase throughput of sand used to make bricks and concrete for centuries to come. Fortunately, we can measure throughput and increases in throughput efficiency for individual components of heterogeneous nature in the Sraffa framework just as easily as when we pretended that nature was homogeneous and could be measured in greens. In which case our "rules" for achieving sustainability become:

- For any component of heterogeneous nature (such as sand) for which current levels of throughput are still lower than a level that is sustainable, $\rho(1)$ can exceed $\rho(n)$ for the time being.

- For any component of heterogeneous nature (such as water) for which current levels of throughput are barely sustainable, $\rho(n)=\rho(1)$ is both necessary and sufficient to maintain sustainability.

- For any component of heterogeneous nature (such as greenhouse gas storage capacity) for which current levels of throughput are already higher than a level that is sustainable, $\rho(n)>\rho(1)$ is required to reachieve sustainability.

\footnotetext{
${ }^{13}$ However, saying that throughput and increases in throughput efficiency for particular environmental services can be easily measured in a Sraffa framework in theory is not to say that this would be easy to do in practice. Finding appropriate data bases and carrying out necessary calculations would no doubt prove difficult. Nonetheless, in theory the Sraffa framework extends easily to multiple services from the environment, including sink services.
} 
Finally, what can we say about environmental sustainability when we recognize not only that nature is heterogeneous, but also that some of nature's heterogeneous "services" are, for all intents and purposes, nonreproducible, i.e. for these services $\mathrm{REG}=0$ ? It is true that we can search for more iron ore, go to greater lengths to extract it from places once thought impenetrable, and make do with lower grades of ore. Nonetheless, there is a difference between iron ore and trees which has long been recognized when we classify trees as a reproducible natural resource and oil as a nonreproducible natural resource. Strictly speaking the existence of nonreproducible natural resources required for production means that environmental sustainability is impossible. But this does not mean that a sustainable strategy is impossible. And we have already begun to describe what such a sustainable "coping strategy" looks like.

Just as we need to search for new technologies that increase environmental throughput efficiency in general, we need to search for new technologies that substitute renewable throughput for non-renewable throughput, and nonrenewable throughput that is farther from exhaustion for non-renewable throughput nearing exhaustion. Similarly, just as we need to adjust our output vector $\mathbf{x}$ to substitute less throughput intensive goods for more throughput intensive goods, we need to adjust $\mathbf{x}$ to substitute throughputs from nature that regenerate for ones that do not, and we need to adjust $\mathbf{x}$ to substitute throughputs from nature that may be non-reproducible but are farther from exhaustion for non-reproducible services that are nearing exhaustion.

But is all this "shucking and jiving" pointless if sustainability is ultimately impossible? Not at all! Even in a worst case scenario in which there is a nonreproducible service from nature that proves to be impossible for human production activities to do without - i.e. that remains "basic" because no change in technology or adjustment in $\mathbf{x}$ permit us to do without it altogether -- "ultimately" can be a very, very long way off. And in a "better case" scenario we may be able to keep eliminating the need for each nonreproducible service from nature before it is exhausted "endlessly."

Moreover, obsessing on all this only distracts us from the challenge at hand, which is to change technologies to increase carbon throughput efficiency and adjust $\mathbf{x}$ so as to eliminate the use of all fossil fuels ASAP -- because we have already exhausted nature's capacity to store greenhouse gases in the 
upper atmosphere. Fortunately, there is no physical reason this cannot be done using known technologies while simultaneously improving economic wellbeing. All that is lacking is the will to do what can, and must be done.

\section{References}

Ayres, R., and A. Kneese. 1969. Production, consumption and externalities. American Economic Review 59: 282-97

Baumgärtner, S., and F. Jost. 2000. Joint production, externalities, and the regulation of network externalities. Environmental and Resource Economics 16: 229-251.

Gehrke, C., and C. Lager. 1995. Environmental taxes, relative prices and choice of technique in a linear model of production. Metroeconomica 46 (2): 127-145.

Hahnel, R. 2013. The growth imperative: beyond assuming conclusions. Review of Radical Political Economics (45, 1): 24-41.

Hahnel, R. 2016a. A tale of three theorems. Review of Radical Political Economics, forthcoming.

Hahnel, R. 2016b. Income Distribution and Environmental Sustainability in a Sraffian Framework. Under review at Harvard University Press.

Kurz, H., and N. Salvadori. 1995. Theory of Production: a Long Period Analysis. Cambridge UK: Cambridge University Press.

Neumann, J. von. 1945. A model of general equilibrium. Review of Economic Studies 13 (1): 1-9.

Okishio, N. 1961. Technical changes and the rate of profit. Kobe University Economic Review 7: 85-99.

Parinello, S. 1983. "Exhaustible natural resources and the classical method of long-period equilibrium" in J. Kregel, ed. Distribution, Effective Demand, and International Economic Relations. London: Macmillan. 
Pasinetti, L., ed. 1980. Essays on the Theory of Joint Production. London: Macmillan.

Pethig, R. 2003. The 'materials balance approach' to pollution: its origin, implications and acceptance. Volkswirtschaftliche Diskussionsbeiträge, No. 105-03, available at: http://hdl.handle.net/10419/83204.

Perrings, C. 1986. Conservation of mass and instability in a dynamic economy-environment system. Journal of Environmental Economics and Management 13: 199 - 211.

Perrings, C. 1987. Economy and Environment: a Theoretical Essay on the Interdependence of Economic and Environmental Systems. Cambridge UK: Cambridge University Press.

Ravagnani, F. 2008. "Classical theory and exhaustible natural resources: Notes on the current debate." Review of Political Economy 20 (1): 79-93.

Roemer, J. 1981. Analytical Foundations of Marxian Economic Theory. Cambridge UK: Cambridge University Press.

Schefold, B. 1971. Mr. Sraffa on Joint Production, private printing (Basel.)

Schefold, B. 1985. Ecological problems as a challenge to classical and Keynesian economics. Metroeconomica 37 (1): 21-61.

Schefold, B. 1989. Mr. Sraffa on Joint Production and Other Essays. London: Unwin Hyman.

Schor, J. 1993. The Over Worked American: the Unexpected Decline of Leisure. New York NY: Basic Books.

Schor, J. 1999. The Over Spent American: Why We Want What we Don't Need. New York NY: Harper Perennial.

Sraffa, P. 1960. Production of Commodities by Means of Commodities. Cambridge UK: Cambridge University Press. 